\title{
Study on the plasticity and sintering properties of electrolytic manganese residue
}

\author{
Mou sheng Song *1, a , Jin yu Yang ${ }^{1, b}$, Jie Zhang ${ }^{1, c}$ \\ ${ }^{1}$ Department of Physics and Electronic Engineering, Tongren University, Tongren 554300, China \\ *Corresponding author: axhy614@163.com, b1471958146@qq.com, c1241631504@qq.com
}

Keywords: EMR; XRD; Plasticity; Sintering; Microstructure

Abstract: Electrolytic manganese residue (EMR) is an acid filter residue and contains a large amount of hazardous substances. The plasticity and sintering properties of EMR heated at 920-1020 $\mathrm{C}$ are measured. EMR primarily consists of quartz $\left(\mathrm{SiO}_{2}\right)$ and chemical gypsum $\left(\mathrm{CaSO}_{4} \cdot 2 \mathrm{H}_{2} \mathrm{O}\right)$, and has a high plasticity. The water absorption and porosity increased but the density and the bending strength decreased with the sintering temperature rising at 920-980 ${ }^{\circ} \mathrm{C}$. Inversely, the water absorption and porosity of sample decreased but the density and strength increased at $980-1020^{\circ} \mathrm{C}$, and it has the maximum density $\left(1.439 \mathrm{~g} / \mathrm{cm}^{3}\right)$ and maximum strength $(8.7 \mathrm{MPa})$. Once sintered above $980^{\circ} \mathrm{C}$, some liquid phases appear and lead to shrinkage and cracking, indicating the failure of continuous sintering.

\section{Introduction}

Electrolytic manganese residue (EMR) belongs to a kind of acid filter residue produced in the production process of electrolytic metal manganese ${ }^{[1]}$. EMR contains a large number of the heavy metallic ions, the solubility salts and other solid mineral compositions such as sulphates, ammonia-nitrogen and water solubility $\mathrm{Mn}^{2+}, \mathrm{Cu}, \mathrm{Zn}, \mathrm{Cr}, \mathrm{Pb}, \mathrm{As}$, Co et.al hazardous substances. The damaging exploitation and excessive digging of the manganese-ore have given rise to the increasingly decline of manganese-ore grade, and per 1 ton electrolytic manganese can produce 9-11 tons acid-soaking $\mathrm{EMR}^{[2]}$. If landfilled directly in air, Mn-residue even shows the slurry-like due to the higher water content. At present, there is still no good ways to treat the Mn-residue, and the large-scale stacking and landfill is still the valid and direct method for Mn-residue. As a result, it brings to many harms such as the land occupation, the pollution of underground/surface water, and the serious deterioration of soil/air environment due of some poisonous elements inside the Mn-residue ${ }^{[3]}$, which restricts the healthy and sustainable development of the manganese industry.

\section{Experimental procedures}

After dried at $80^{\circ} \mathrm{C}$ for $8 \mathrm{~h}$ and thoroughly mixed by ball milling, the raw Mn-residue powder was then uniaxially pressed into a cylindrical compact $(\Phi 80 \times 8 \mathrm{~mm})$ under $40 \mathrm{MPa}$ pressure and a cubical compact $(37 \mathrm{~mm} \times 6.5 \mathrm{~mm} \times 6.5 \mathrm{~mm})$ under $25 \mathrm{MPa}$ pressure, respectively. The phase was identified by X-ray diffractometer (Model DX-2700), and the plasticity index was measured by plasticity tester (Model KSB). The sample was pressurelessly sintered at $920-1020^{\circ} \mathrm{C}$ and then soaked at the peak temperature for $2 \mathrm{~h}$. The water absorption $\left(W_{\mathrm{a}}\right)$, porosity $\left(P_{\mathrm{a}}\right)$ and density $(D)$ were measured by Digital Ceramic Water-absorption tester (Model TXY) with the Archimedes method. The bending strength was measured by the electric general materials instrument (Model RGM-4100), and the microstructure was observed by scanning electron microscope (Model JSM-5610LV). 


\section{Results and discussion}

\section{XRD analysis}

Fig. 1 shows the phase identification of the Mn-residue powder, which exhibits its phase constituents mainly including the quartz $\left(\mathrm{SiO}_{2}, \mathrm{PDF}\right.$ no.: 65-0466) and gypsum, namely calcium sulphate dihydrate $\left(\mathrm{CaSO}_{4} \cdot 2 \mathrm{H}_{2} \mathrm{O}\right.$, PDF no.: 33-311). The both characteristic spectral lines keep rather keen-edged, indicating the Mn-residue having a well crystal habit. Due to the higher calcium sulphate content, the Mn-residue belongs to the industrial gypsum waste. Additionally, some weaker wide peaks among the XRD patterns probably result from the noncrystalline ores among the diverse compositions of raw manganese mine,

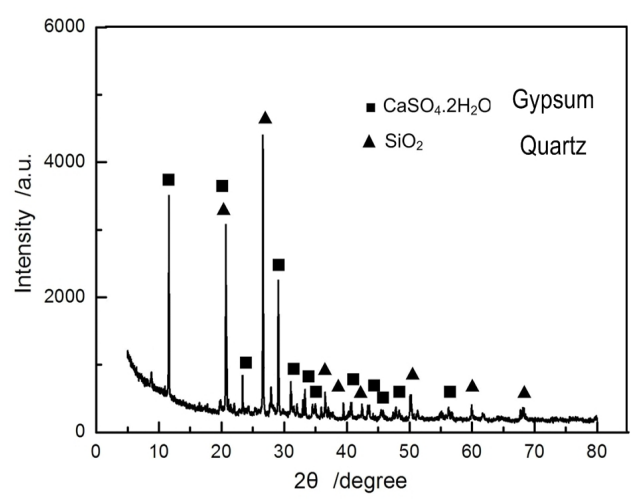

Fig. 1 XRD pattern of raw Mn-residue. or other trace mines not detected by XRD because the production process of electrolytic manganese did not generate new noncrystalline ores. Qian's ${ }^{[4]}$ work declared that Mn-residue mainly contains quartz and gypsum, and small hehatite, and can replace plaster using as the cement retarder.

\section{Plasticity}

The plasticity of ceramic mud-pie plays an important role in controlling the forming process for ceramic green body. Generally, the plasticity of clay mud-pie is denoted by plasticity index. The plasticity index exceeds 3.6 for the high plasticity clay, lies at 2.5-3.6 for the middle plasticity clay, and is less than 2.5 for the low plasticity clay ${ }^{[5]}$.

Three Mn-residue mud-balls with various water contents ( $75 \mathrm{~g}$ per ball with $\Phi 45 \pm 1 \mathrm{~mm}$ diameter) were aged various times (0,1,2, 3 and 5 days). Fig. 2 shows the plasticity index of Mn-residue mud-balls with various aged times and water contents. As seen, with the aged time increasing, the plasticity indexes of mud-balls decreased linearly. All plasticity indexes of mud-balls aged within 2 days exceeded 3.6, and those of mud-balls aged within 5 days exceeding 3.6 were over $21 \%$, which means Mn-residue exhibiting rather high plasticity. Furthermore, the water content reveals the evident influence on the plasticity of Mn-residue, and too high or too low water content is not always advantageous for the plasticity. The mud-pie plasticity is closely linked to the mineral type, the particle size and shape, and the categories of adsorbing cation, namely to the hydration shell thickness formed around the particles. The too much water will generate fluxion and thus lose the plasticity. Otherwise, the too low water will lead the continuous hydration shell to fracture, the internal

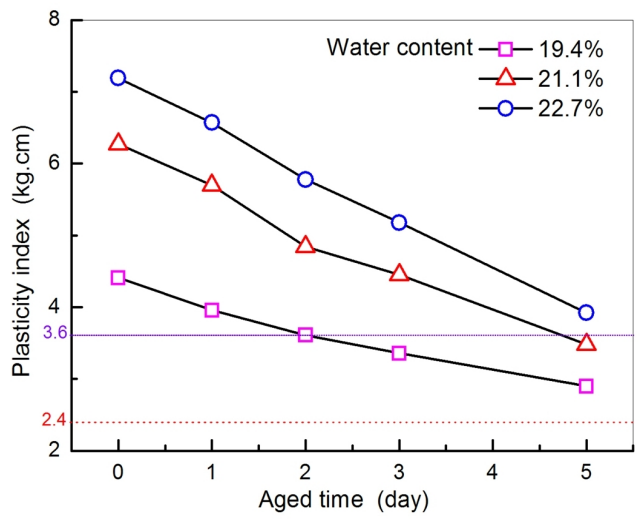

Fig. 2 Plasticity index of $\mathrm{Mn}$-residue with various aged time and water content. friction to elevate, the plasticity to fall, even to emerge the loose state under the lower pressure.

\section{Sintering properties}

Fig. 3 shows the appearance of sample sintered at $920-1020^{\circ} \mathrm{C}$. As seen, the appearance primarily takes on the drab. Relative to the upper surface, the lower surface shows the thick puce owing to the heterogeneous sintering atmosphere, which is maybe concerned with the gas emitting and discharging produced by sintering process. The decomposed $\mathrm{SO}_{3}$ gas easily volatilize and is a kind of poisonous and thick pungent smell gas, if letting out to the air will bring to the serious environment pollution. So burning the Mn-residue, it must consider the $\mathrm{SO}_{3}$ discharging, in case the 
second pollution generated by Mn-residue sintering. When the temperature exceeds $1000^{\circ} \mathrm{C}$, the sample occurred the obvious shrinkage, cracking and deformation, meaning the continue sintering failure.

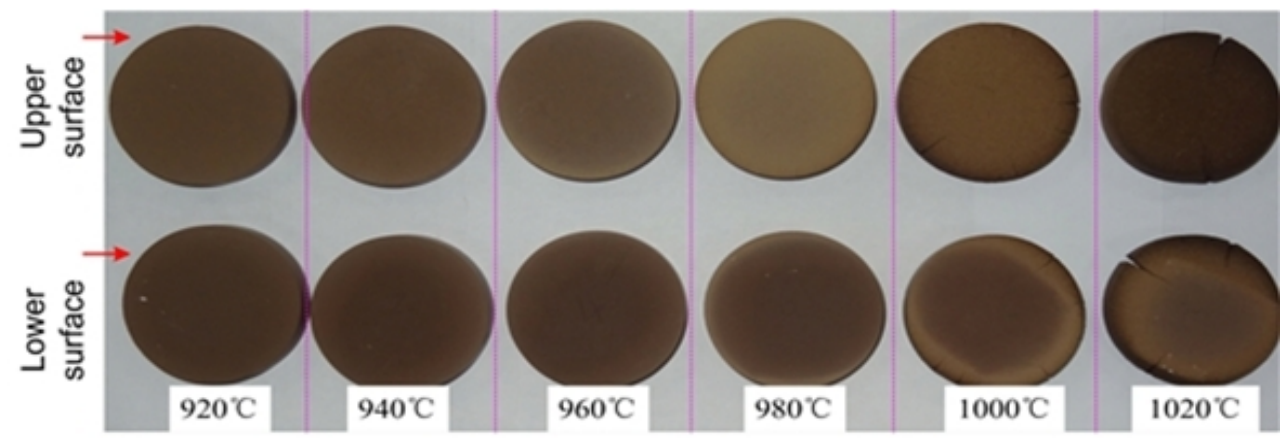

Fig. 3 Macro-shapes of Mn-residue compacts at various sintering temperature.

The water absorption, porosity and bulk density are the key parameters to evaluate the ceramic sintering materials, especially for those of industrial slag compact. The crystal water in the Mn-residue is rather difficult to remove in spite of the free water can remove through the long-time drying. Fig. 4 shows the water absorption, porosity and bulk density at various sintering temperature. At $920-980^{\circ} \mathrm{C}$, the $W_{\mathrm{a}}$ and $P_{\mathrm{a}}$ of Mn-residue burning samples gradually increased with temperature rising and reached the maximum at $980^{\circ} \mathrm{C}$, which is linked to the dehydration of calcium sulphate dihydrate and the ceaseless volatilization of $\mathrm{SO}_{3}$ gas from calcium sulphate decomposition. However, the $W_{\mathrm{a}}$ and $P_{\mathrm{a}}$ gradually decreased instead once temperature exceeds $980^{\circ} \mathrm{C}$. When sintered at $1000^{\circ} \mathrm{C}$ and $1020^{\circ} \mathrm{C}$, the volatilization of $\mathrm{SO}_{3}$ gas has finished, and the liquid phase melting became more and more. These liquid phases will endlessly infiltrate and diffuse, and hence fill and stuff the formed much pores, which makes the $W_{\mathrm{a}}$ and $P_{\mathrm{a}}$ fall down. Due to the same reason, the bulk density of sample appears opposite change trend, and obtains the maximum of $1.439 \mathrm{~g} / \mathrm{cm}^{3}$. However, during the temperature falling, these liquid phases will solidify and generate the stronger internal stress to make the burning compact produce more cracks and fractures. As a result, for the single burning of Mn-residue, it is not always favorable for the sintering properties once temperature exceeds $980^{\circ} \mathrm{C}$.

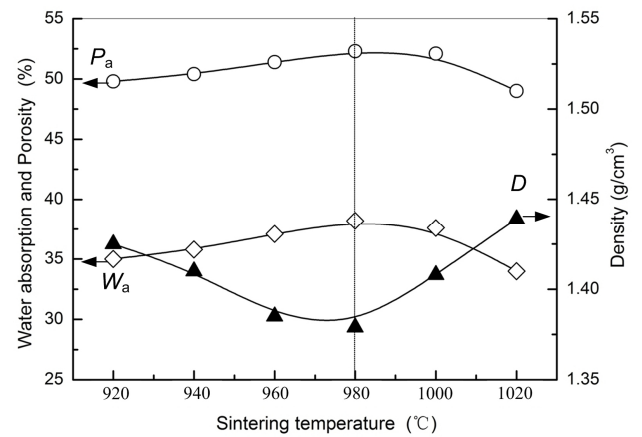

Fig. 4 Water absorption, porosity and density of sintered Mn-residue at various temperatures.

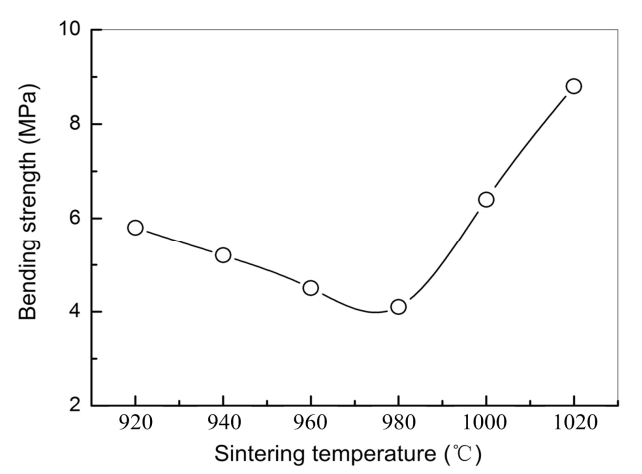

Fig. 5 Bending strength of sample at various temperatures.

\section{Bending strength and microstructure}

Fig. 5 shows the bending strength at various temperatures. Clearly, the bending strength gradually decreased at $920-980^{\circ} \mathrm{C}$, but increased sharply at $980-1020^{\circ} \mathrm{C}$ and reached the maximum value $(8.7 \mathrm{MPa})$. This bending strength reversion is related to the porosity change and the liquid phase appearance. Commonly, the strength of ceramic materials reduces with the porosity rising and increases with the liquid phase increasing. The amount, size, shape and distribution of pore all have the evident influence on the strength. At $920-980^{\circ} \mathrm{C}$, no appearance of liquid phase and the increasing porosity will lead the bending strength to lower down. At the same time, because of the volatilization of impurity connected with other particles inside Mn-residue and the $\mathrm{CaSO}_{4}$ decomposing into $\mathrm{CaO}$ 
and $\mathrm{SO}_{3}$, the binding force among Mn-residue particles lower down and the internal stress resistance to deformation fall too, which leads the bending strength to gradually decrease. On the contrary, at $980-1020^{\circ} \mathrm{C}$, the porosity gradually reduces. In particularly, the presence and increase of liquid phase can fill into the pores and adhere the particles each other to form a uniform and tight structure, and thus increase the bending strength. On the other hand, when the rapid increased molten phase cooled down, the coefficient difference of linear expansion within the sample will tear the sintered body during solidification, which results in the sintering sample producing more and larger macro-cracks.
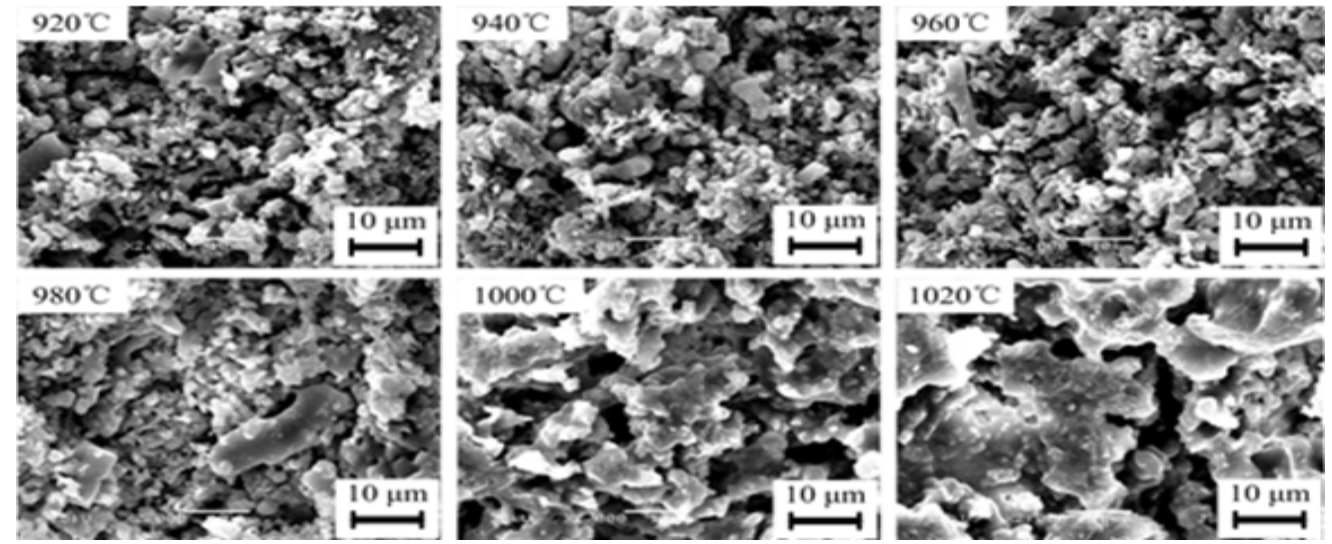

Fig. 6 Fractured Microstructures of samples sintered at various temperatures.

The fractured microstructure of sample sintered at different temperatures is revealed in Fig. 6. At 920-980 ${ }^{\circ} \mathrm{C}$, the particles in the fractured surface take on the loose status and the pores become more and larger. But at $980-1020^{\circ} \mathrm{C}$, the pores decrease obviously and there appears many coagulated clumps filling into the pores and adhering with each other, meaning the Mn-residue melting. It is suggested that the mineral composition of $\mathrm{Mn}$-residue should contain some transparent or semitransparent glassy body. After sintered, a few of the well-developed crystalline phase means that Mn-residue belongs to an industrial solid waste with some potential activity. It is the liquid phase increase that leads the $W_{\mathrm{a}}$ and $P_{\mathrm{a}}$ of sintered samples to unceasingly lower down once above $980^{\circ} \mathrm{C}$, inversely the bulk density and bending strength continuously elevate. It is unfavorable for only Mn-residue to continuously heat above $1000^{\circ} \mathrm{C}$ owing to the appearance of many macro-cracks.

\section{Summary}

The Mn-residue mainly consists of quartz and gypsum and reveals the high plasticity. Sintered at 920-1020 ${ }^{\circ} \mathrm{C}$, the $W_{\mathrm{a}}, P_{\mathrm{a}}$, densification and bending strength of samples are closely linked to the $\mathrm{Mn}$-residue melting. It is unfavorable for only Mn-residue to continuously heat above $1000^{\circ} \mathrm{C}$.

\section{Acknowledgements}

This work was financially supported by the Collaborative Fund of Science and Technology of Guizhou (Grant No. LH[2016]7293), and also by the Training Program of Innovation and Entrepreneurship for Undergraduates of Guizhou (Grant No. 201710665007).

\section{References}

[1] M. S. Li, Y.P. Luo and Z.Y. Su: Enviro. Pollu Vol. 147 (2007), p. 168

[2] B. Du, Z.G. Ru and Z.G. Dan: J. Guilin. Univ. Techn Vol. 35 (2015), p. 152

[3] F.A.B. Canuto, C.A.B. Garcia and J.P.H. Alves: Enviro. Moni. Asse Vol. 185 (2013), p. 6173

[4] J.S. Qian, P.K. Hou and Z. Wang: Mater. Rev Vol. 23 (2009), p. 59

[5] F.P. Xu, X.H. Zhou and T.X. Hu: Exp. Inf. Mini. Ind Vol. 3 (2007), p. 4 